\title{
Catalytic Activity of Dual Metal Cyanide Complex in Multi-component Coupling Reactions
}

\author{
Anaswara RAVINDRAN, Rajendra SRIVASTAVA* \\ Department of Chemistry, Indian Institute of Technology Ropar, Rupnagar 140001, India
}

\begin{abstract}
Several dual metal cyanide catalysts were prepared from potassium ferrocyanide, metal chloride (where metal $=\mathrm{Zn}^{2+}, \mathrm{Mn}^{2+}, \mathrm{Ni}^{2+}$, $\mathrm{Co}^{2+}$ and $\mathrm{Fe}^{2+}$ ), $t$-butanol (complexing agent) and PEG-4000 (co-complexing agent). The catalysts were characterized by elemental analysis (CHN and X-ray fluorescence), X-ray diffraction, $\mathrm{N}_{2}$ adsorption-desorption, scanning electron microscopy, Fourier-transform infrared spectroscopy, and UV-Visible spectroscopy. The dual metal cyanide catalysts were used in several acid catalyzed multi-component coupling reactions for the synthesis of pharmaceutically important organic derivatives. In all these reactions, the Fe-Fe containing dual metal cyanide catalyst was the best catalyst. The catalysts can be recycled without loss in catalytic activity. The advantage of this method is the use of mild, efficient and reusable catalysts for various reactions, which makes them candidates for commercial use.
\end{abstract}

Key words: dual metal cyanide; multi-component coupling reaction; acid catalyst

CLC number: O643 Document code: A

Received 9 May 2011. Accepted 30 July 2011.

*Corresponding author. Tel: +91-1881-242175; Fax: +91-1881-223395; E-mail: rajendra@iitrprac.in

The authors thank the Ministry of Human Resource and Development, New Delhi and Director, IIT Ropar for financial assistance.

English edition available online at Elsevier ScienceDirect (http://www.sciencedirect.com/science/journal/18722067).

Dual metal cyanide (DMC) catalysts are a class of molecular salts comprising a metal-cyanide crystalline framework with two different metal centers. They have the general formula $\mathrm{M}^{1}{ }_{u}\left[\mathrm{M}^{2}(\mathrm{CN})_{6}\right]_{v} \cdot y \mathrm{~L} \cdot z \mathrm{H}_{2} \mathrm{O}$ (where $\mathrm{M}^{1}=\mathrm{Zn} ; \mathrm{M}^{2}$ $=\mathrm{Co}, \mathrm{Fe}$ etc.; $\mathrm{L}=$ organic complexing agent) $[1-4]$. DMC catalysts possess zeolite-like cage structures [5], and have gained considerable attention for their interesting magnetic, electrochromic, magneto-optic, photomagnetic, and nanomagnetic properties [6]. DMC catalysts are insoluble in organic solvents, acids, and even in aqua regia. They are usually prepared by the precipitation reaction of an aqueous solution of a water-soluble metal salt $\left(\mathrm{M}_{u}{ }^{1} \mathrm{X}_{w}\right)$, metal cyanide potassium salt $\left(\mathrm{K}_{a}\left[\mathrm{M}(\mathrm{CN})_{n}\right]_{v}\right)$, and a water-soluble organic complexing agent (L).

DMC catalysts were discovered in the 1960's [7] and were found to have significant catalytic activity in various reactions, in particular in polymerization reactions [8-14]. DMC complexes find extensive applications in the ring opening polymerization of epoxides [1-4]. DMC catalysts can be used to produce polyether, polyester, and poly (ether ester) polyols [8-11]. Environmentally friendly synthesis of biodegradable polycarbonates was realized using DMC catalysts by the copolymerization of epoxide with $\mathrm{CO}_{2}$ $[12,13]$. They have been relatively well investigated with respect to their activity using different preparation routes and operating conditions $[12,14]$. The recent literature suggest that they can be effectively utilized in esterification and transesterification reactions for the production of organic carbonates and biodiesel $[15,16]$.

Multi-component reactions are a powerful and useful synthetic tool to produce complex molecules from simple precursors by a one-pot procedure [17-19]. In this procedure, there is no need to isolate any intermediate, and there is reduction in the reaction time and savings in both energy and raw materials. Therefore, the design of novel multi-component reactions has attracted a great deal of attention from research groups working in the field of medicinal chemistry, drug discovery, and material science.

To utilize DMC in chemical synthesis, Fe-Zn based DMC catalysts have been prepared by varying several synthesis parameters $[15,16]$. However, the influence on reactivity of changing the metal ions in the DMC has not been explored. The objective of this study is to prepare a variety of DMC catalysts and assess their catalytic activity in chemical synthesis. A variety of Fe-M-containing DMC catalysts $(\mathrm{M}=$ $\mathrm{Fe}, \mathrm{Mn}, \mathrm{Co}, \mathrm{Ni}$, and $\mathrm{Zn}$ ) were prepared (with all other synthesis parameters the same). Their catalytic activities were assessed using multi-component coupling reactions in the synthesis of pharmaceutically important organic derivatives, in particular, the synthesis of $N$-[(2-hydroxy-naphthalen1-yl)-aryl-methyl]-benzamide/urea (3-component coupling product of aromatic aldehyde, $\beta$-naphthol, and benzamide/urea), 1-(aryl (piperidin-1-yl) methyl) naphthalen-2-ol (3-component coupling product of aromatic alde- 
hyde, $\beta$-naphthol, and piperidine), and 5-(ethoxycarbonyl)6-methyl-4-aryl-3, 4-dihydropyrimidin-2(1H)-one (3-component coupling product of aromatic aldehyde, ethylacetoacetate, and urea).

\section{Experimental}

\subsection{Catalyst preparation}

In a typical synthesis, $0.01 \mathrm{~mol}$ potassium ferrocyanide, $\left(\mathrm{K}_{4}\left[\mathrm{Fe}(\mathrm{CN})_{6}\right] \cdot 3 \mathrm{H}_{2} \mathrm{O}\right.$, Merck, India) was dissolved in $40 \mathrm{ml}$ double-distilled water to prepare solution 1 . In a separate beaker, solution 2 was prepared by dissolving $0.1 \mathrm{~mol}$ metal chloride salts $\left(\mathrm{ZnCl}_{2}, \mathrm{MnCl}_{2} \cdot 4 \mathrm{H}_{2} \mathrm{O}, \mathrm{NiCl}_{2} \cdot 6 \mathrm{H}_{2} \mathrm{O}, \mathrm{CoCl}_{2}\right.$. $6 \mathrm{H}_{2} \mathrm{O}$, and $\mathrm{FeCl}_{2} \cdot 4 \mathrm{H}_{2} \mathrm{O}$ ) in $100 \mathrm{ml}$ distilled water and $20 \mathrm{ml}$ $t$-BuOH. Polyethylene glycol (15 g, PEG-4000) was dissolved in a third beaker containing $2 \mathrm{ml}$ distilled water and $40 \mathrm{ml} t$-BuOH to prepare solution 3. Solution 2 was added to solution 1 slowly over $1 \mathrm{~h}$ at $323 \mathrm{~K}$ under vigorous stirring. Precipitation of a solid occurred during the addition. To the reaction mixture, solution 3 was added over 5-10 minutes and stirring was continued for another $1 \mathrm{~h}$. The solid that was formed was filtered and washed thoroughly with $500 \mathrm{ml}$ double-distilled water to remove uncomplexed ions, and dried at $398 \mathrm{~K}$ for several hours. The DMC catalysts prepared with $\mathrm{K}_{4}\left[\mathrm{Fe}(\mathrm{CN})_{6}\right]$ and different metal chlorides were designated as Fe-Zn-PEG, Fe-Mn-PEG, Fe-Ni-PEG, Fe-Co-PEG, and Fe-Fe-PEG. The colors of these catalysts were: Fe-Zn-PEG (white), Fe-Fe-PEG (dark blue), Fe-Mn-PEG (light green), Fe-Ni-PEG (olive green), and Fe-Co-PEG (brown). $t$-BuOH acted as a complexing agent and PEG-4000 acted as a co-complexing agent.

\subsection{Catalytic reactions}

\subsubsection{Synthesis of $N$-[(2-hydroxynaphthalen-1-yl)-aryl- methyl]-benzamide and $N$-[(2-hydroxynaphthalen-1-yl)- aryl-methyl]-urea}

A mixture of $\beta$-naphthol (10 mmol), aldehyde (10 mmol), benzamide/urea $(12 \mathrm{mmol})$, and catalyst $(0.5 \mathrm{mmol})$ was stirred in the presence of 1,2-dichloroethane $(15 \mathrm{ml})$ at 353 $\mathrm{K}$ for the desired time. The progress of the reaction was monitored by thin layer chromatography (TLC). 1,2-dichloroethane $(30 \mathrm{ml})$ was added into the reaction mixture, and the catalyst was filtered and washed with chloroform for reuse. The organic layer was successively washed with water $(30 \mathrm{ml})$, sat. $\mathrm{NaHCO}_{3}(30 \mathrm{ml})$, water (30 $\mathrm{ml}$ ) and then dried over anhydrous sodium sulfate. The solvent was evaporated to get the crude compound in almost pure form. The product was further purified by re-crystallization from ethanol/ $\mathrm{H}_{2} \mathrm{O}$. The compounds were characterized by IR, ${ }^{1} \mathrm{H}$ NMR $\left(\mathrm{CDCl}_{3}\right)$, elemental analysis and melting point, and the results matched well with the reported values [20].

$N$-[(2-hydroxynaphthalen-1-yl)-phenylmethyl]-benzamid e. Mp 233-235 ${ }^{\circ} \mathrm{C}$. IR $\left(\mathrm{KBr}, v, \mathrm{~cm}^{-1}\right)$ : 3422, 3064, 3023, $1628,1576,1530,1438,1345,1270,826 .{ }^{1} \mathrm{H}$ NMR (200 MHz, DMSO-d $\left.{ }_{6}\right) \delta 5.32$ (br s, $\left.1 \mathrm{H}\right), 5.78$ (br s, $\left.1 \mathrm{H}\right)$, 7.24-8.13 (m, 16H), $10.04(\mathrm{~s}, 1 \mathrm{H})$; Elemental analysis for $\mathrm{C}_{24} \mathrm{H}_{19} \mathrm{NO}_{2}$ : (\%) C 81.81, H 5.12, N 3.77 (theoretical: $\mathrm{C}$ $81.58, \mathrm{H}$ 5.38, N 3.96).

$\mathrm{N}$-[(2-hydroxynaphthalen-1-yl)-phenylmethyl]-urea. Mp $175-177{ }^{\circ} \mathrm{C}$. IR (KBr, $\left.v, \mathrm{~cm}^{-1}\right): 3455,3360,3200,2240$, 1630, 1580, 1510, 1426, 1372, 1238, 814. ${ }^{1} \mathrm{H}$ NMR (200 MHz, DMSO-d 6 ) $\delta 5.30$ (br s, 1H), 5.72 (br s, 1H), 6.91 (br $\mathrm{s}, 2 \mathrm{H}), 7.12-7.82(\mathrm{~m}, 11 \mathrm{H}), 10.25(\mathrm{~s}, 1 \mathrm{H})$; Elemental analysis for $\mathrm{C}_{18} \mathrm{H}_{16} \mathrm{~N}_{2} \mathrm{O}_{2}$ : (\%): C 74.39, H 5.39, N 9.32 (theoretical: C 73.96, H 5.52, N 9.58).

\subsubsection{Synthesis of 1-(aryl-(piperidin-1-yl) methyl) naphthalen-2-ol (Betti base)}

A mixture of $\beta$-naphthol (10 mmol), aldehyde (13 mmol), piperidine $(10 \mathrm{mmol})$, and catalyst $(0.5 \mathrm{mmol})$ was stirred in the presence of water $(15 \mathrm{ml})$ at $298 \mathrm{~K}$ for the desired time. The progress of the reaction was monitored by TLC. After 4 $\mathrm{h}$ of reaction, the reaction mixture was extracted by ethyl acetate. The aqueous phase was back-extracted with ethyl acetate. The combined organic layers were dried over anhydrous $\mathrm{Na}_{2} \mathrm{SO}_{4}$, filtered, and concentrated under reduced pressure to get the crude product as a white solid which was purified by column chromatography using silica gel $(60-120)$ as the stationary phase with hexane/ethyl acetate (95/5). The compounds were characterized by IR, ${ }^{1} \mathrm{H}$ NMR, elemental analysis, and melting point and the results matched well with the reported values [21].

Mp $180-181{ }^{\circ} \mathrm{C}$. IR (KBr, $\left.v, \mathrm{~cm}^{-1}\right): 3057,2942,2844$, 1621, 1450, 751. ${ }^{1} \mathrm{H}$ NMR (200 MHz, $\left.\mathrm{CDCl}_{3}\right) \delta 1.66$ (br s, $6 \mathrm{H}), 2.43-2.53$ (br s, 4H), $5.07(\mathrm{~s}, 1 \mathrm{H}), 7.05-7.81(\mathrm{~m}, 10 \mathrm{H})$, $7.85(\mathrm{~d}, \mathrm{~J}=8.4 \mathrm{~Hz}, 1 \mathrm{H}), 10.01(\mathrm{~s}, 1 \mathrm{H})$; Elemental analysis for $\mathrm{C}_{22} \mathrm{H}_{23} \mathrm{NO}$ : (\%) C 83.41, H 7.18, N 4.31 (Theoretical: C 83.28, H 7.25, N 4.41).

\subsubsection{Synthesis of 5-(ethoxycarbonyl)-6-methyl-4-aryl- 3,4-dihydropyrimidin-2(1H)one}

In a typical synthesis, aldehyde (10 mmol), urea (15 $\mathrm{mmol})$, ethylacetoacetate $(10 \mathrm{mmol})$, catalyst $(0.5 \mathrm{mmol})$, and acetonitrile $(10 \mathrm{ml})$ were mixed in a $100 \mathrm{ml}$ flask. The reaction was conducted at $353 \mathrm{~K}$ for $12 \mathrm{~h}$. After completion of the reaction, the catalyst was removed by simple filtration/decantation. The products were isolated by flash column chromatography (petroleum ether/ethyl acetate $=3$ ). 
The compounds were characterized by IR, ${ }^{1} \mathrm{H}$ NMR, elemental analysis and melting point and the results matched well with the reported values [22].

Mp 208-209 ${ }^{\circ} \mathrm{C}$. IR $\left(\mathrm{KBr}, v, \mathrm{~cm}^{-1}\right): 3247,3121,1725$, 1703, 1644, 1225, 1090. ${ }^{1} \mathrm{H}$ NMR $\left(200 \mathrm{MHz}, \mathrm{CDCl}_{3}\right) \delta 9.17$ (s, 1H), $7.75(\mathrm{~s}, 1 \mathrm{H}), 7.20-7.30(\mathrm{~m}, 5 \mathrm{H}), 5.10(\mathrm{~d}, 1 \mathrm{H}), 3.95$ $(\mathrm{q}, 2 \mathrm{H}), 2.20(\mathrm{~s}, 3 \mathrm{H}), 1.07(\mathrm{t}, 3 \mathrm{H})$. Elemental analysis for $\mathrm{C}_{14} \mathrm{H}_{16} \mathrm{~N}_{2} \mathrm{O}_{3}$ : (\%) C 64.84, H 6.05, N 10.92 (theoretical: C 64.60, H 6.20, N 10.76).

\section{Results and discussion}

\subsection{Physico-chemical characterization of the DMC complexes}

The molecular formulas of the DMCs were obtained from $\mathrm{X}$-ray fluorescence (XRF) and elemental analysis data (Table 1). The X-ray diffraction (XRD) pattern for Fe-Zn-PEG revealed that the catalyst was highly crystalline and had no starting compound impurity (Fig. 1). The peak indexing

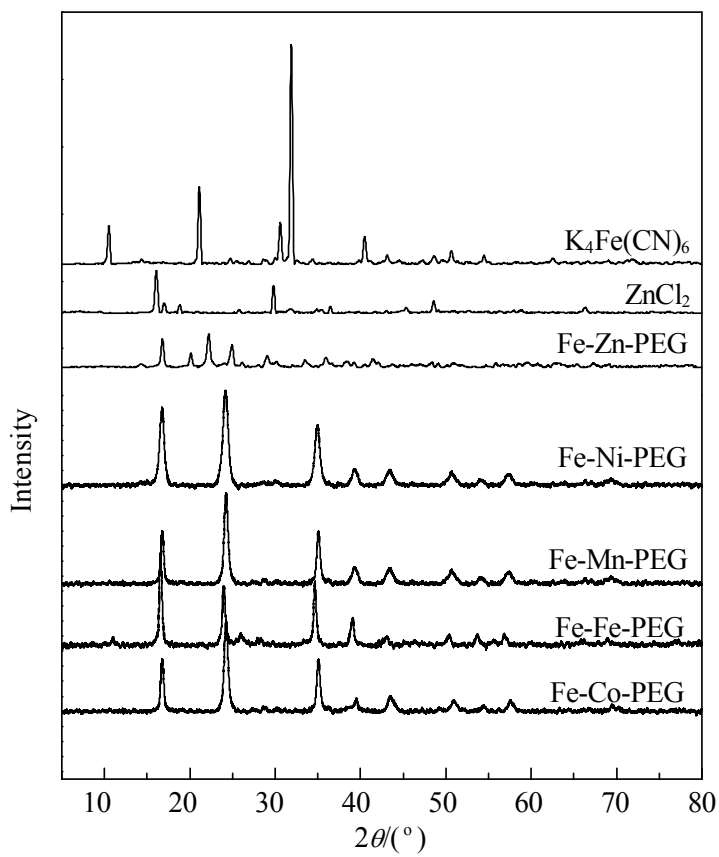

Fig. 1. $\mathrm{XRD}$ profiles of $\mathrm{K}_{4}\left[\mathrm{Fe}(\mathrm{CN})_{6}\right]_{2}, \mathrm{ZnCl}_{2}, \quad \mathrm{Fe}-\mathrm{Zn}$-PEG, Fe-Mn-PEG, Fe-Fe-PEG, Fe-Co-PEG, and Fe-Ni-PEG complexes.
Table 2 Textural properties of the DMC catalysts

\begin{tabular}{lccc}
\hline Complex & $\begin{array}{c}\text { Unit cell parameter } \\
(\mathrm{nm})\end{array}$ & $\begin{array}{c}\text { Surface area } \\
\left(\mathrm{m}^{2} / \mathrm{g}\right)\end{array}$ & $\begin{array}{c}\text { Pore volume } \\
\left(\mathrm{cm}^{3} / \mathrm{g}\right)\end{array}$ \\
\hline Fe-Zn-PEG & 0.78 & 57.9 & 0.22 \\
Fe-Mn-PEG & 0.50 & 76.2 & 0.28 \\
Fe-Fe-PEG & 0.50 & 106.4 & 0.40 \\
Fe-Ni-PEG & 0.50 & 38.7 & 0.14 \\
Fe-Co-PEG & 0.50 & 32.6 & 0.12 \\
\hline
\end{tabular}

showed that the DMC complexes crystallized in a cubic lattice. The cubic unit cell parameters were $0.78 \mathrm{~nm}$ for Fe-Zn-PEG and $0.5 \mathrm{~nm}$ for Fe-Fe-PEG, Fe-Co-PEG, Fe-Mn-PEG, and Fe-Ni-PEG (Table 2, Fig. 1).

The specific surface area $\left(S_{\mathrm{BET}}\right)$ of the calcined Fe-Fe-PEG was $106.4 \mathrm{~m}^{2} / \mathrm{g}$. The Fe-Fe-PEG exhibited a Type IV isotherm with a uniform pore size distribution, which corresponded to mesoporous materials (Fig. 2). The BJH pore size distribution analysis showed that the Fe-Fe-PEG has an average pore diameter of $4.5 \mathrm{~nm}$ (Fig. 2). Fe-Fe-PEG exhibited highest surface area of the DMC catalysts investigated in this study (Table 2). Scanning electron microscopy (SEM) revealed that the Fe-Zn-PEG complex was highly crystalline and had a cube-like tablet morphology (Fig. 3), while the other DMC catalysts had an irregular morphology. The DMC catalysts were nanocrystalline but had different particle sizes. The particle sizes of

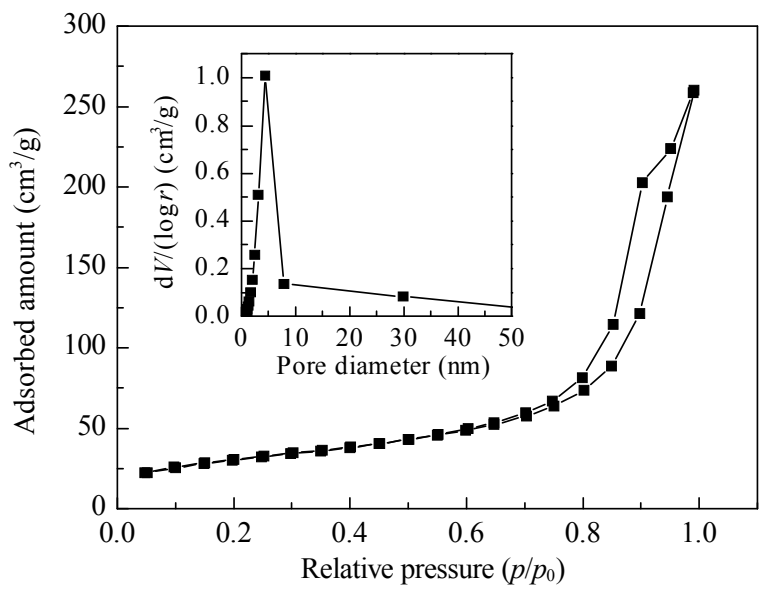

Fig. 2. $\mathrm{N}_{2}$ adsorption-desorption isotherms and pore size distribution of the Fe-Fe-PEG catalyst.

Table 1 Elemental analysis and XRF analysis data of the DMC complexes

\begin{tabular}{|c|c|c|c|c|c|c|c|}
\hline \multirow{2}{*}{ Complex } & \multicolumn{3}{|c|}{ XRF analysis (mol) } & \multicolumn{3}{|c|}{ Elemental analysis (wt $\%$ ) } & \multirow{2}{*}{ Tentative molecular formula } \\
\hline & $\mathrm{Fe}$ & $\mathrm{M}$ & $\mathrm{K}$ & $\mathrm{C}$ & $\mathrm{H}$ & $\mathrm{N}$ & \\
\hline Fe-Zn-PEG & $2.8(3)$ & $3.6(4)$ & $3.7(4)$ & $18.7(17.5)$ & $1.7(1.6)$ & $18.5(20.4)$ & $\mathrm{K}_{4} \mathrm{Zn}_{4}\left[\mathrm{Fe}(\mathrm{CN})_{6}\right]_{3} \cdot 10 \mathrm{H}_{2} \mathrm{O}$ \\
\hline Fe-Mn-PEG & $2.2(2)$ & $3.1(3)$ & $1.8(2)$ & $17.2(16.6)$ & $2.1(2.3)$ & $18.5(19.3)$ & $\mathrm{K}_{2} \mathrm{Mn}_{3}\left[\mathrm{Fe}(\mathrm{CN})_{6}\right]_{2} \cdot 10 \mathrm{H}_{2} \mathrm{O}$ \\
\hline Fe-Fe-PEG & $5.4(5)$ & - & $3.8(4)$ & $15.2(15.5)$ & $1.8(2.1)$ & $17.2(18.1)$ & $\mathrm{K}_{4} \mathrm{Fe}_{3}\left[\mathrm{Fe}(\mathrm{CN})_{6}\right]_{2} \cdot 10 \mathrm{H}_{2} \mathrm{O}$ \\
\hline Fe-Ni-PEG & $2.3(2)$ & $3.1(3)$ & $1.7(2)$ & $16.6(16.8)$ & $2.2(2.4)$ & $19.5(19.6)$ & $\mathrm{K}_{2} \mathrm{Ni}_{3}\left[\mathrm{Fe}(\mathrm{CN})_{6}\right]_{2} \cdot 10 \mathrm{H}_{2} \mathrm{O}$ \\
\hline Fe-Co-PEG & $2.1(2)$ & $3.2(3)$ & $1.9(2)$ & $17.7(16.8)$ & $1.9(2.3)$ & $19.9(19.6)$ & $\mathrm{K}_{2} \mathrm{Co}_{3}\left[\mathrm{Fe}(\mathrm{CN})_{6}\right]_{2} \cdot 10 \mathrm{H}_{2} \mathrm{O}$ \\
\hline
\end{tabular}

The values in parentheses correspond to theoretical estimates. 


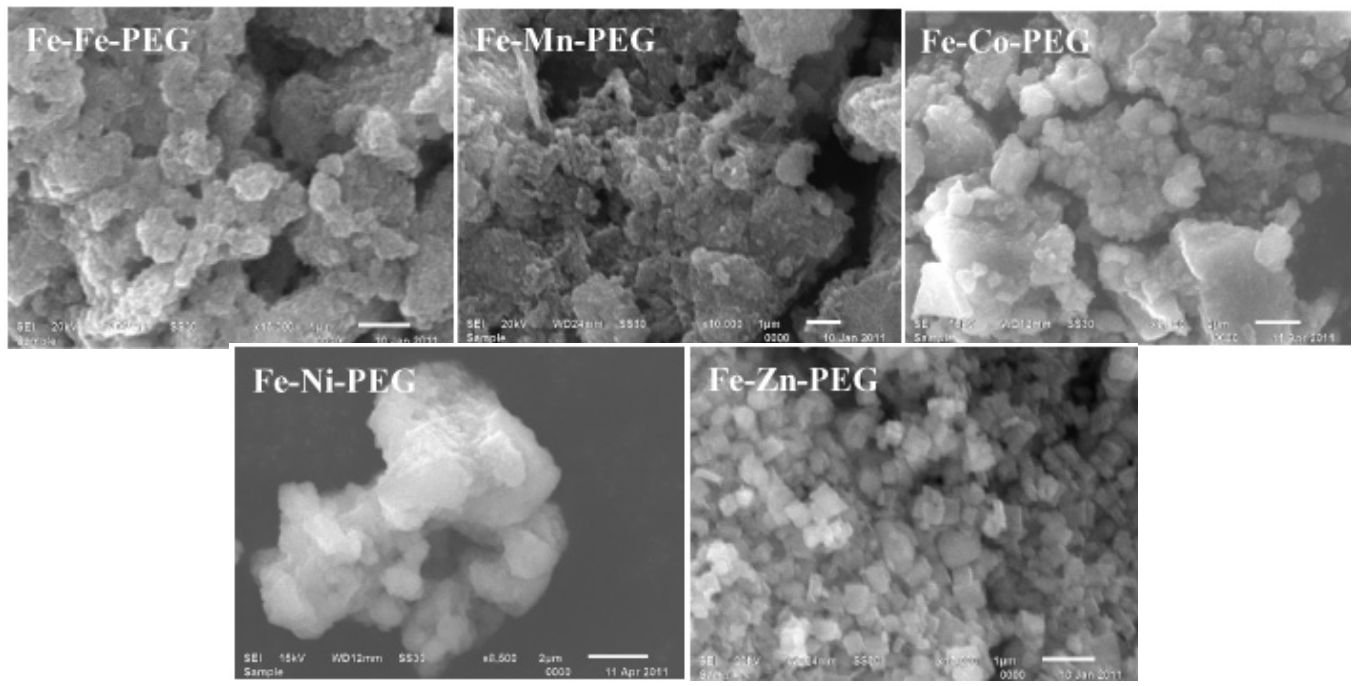

Fig. 3. SEM images of the DMC catalysts.

Fe-Fe-PEG and Fe-Mn-PEG were in the range of 50-100 $\mathrm{nm}$.

The $\mathrm{C} \equiv \mathrm{N}$ band in the IR spectrum depended on the mode of cyanide coordination and the metal to which it was coordinated to [23]. $\mathrm{K}_{4} \mathrm{Fe}(\mathrm{CN})_{6}$ showed an intense characteristic band at $2035 \mathrm{~cm}^{-1}$ due to $v(\mathrm{C} \equiv \mathrm{N})$, which shifted to 2075 $\mathrm{cm}^{-1}$ for the Fe-Fe-PEG catalyst (Fig. 4). The shift in the band from 2035 to $2075 \mathrm{~cm}^{-1}$ in the present study suggested the formation of a new mixed-metal complex of ferrocyanide moiety and $\mathrm{Fe}^{2+}$ ions via bridging cyanide ligands. Cyanide ions act not only as $\sigma$-donors (by donating electron to $\mathrm{Fe}$ ), but also as a $\pi$ donors (by chelating to $\mathrm{Fe}$ ). Electron donation increases $v(\mathrm{C} \equiv \mathrm{N})$ because electrons are removed from the $5 \sigma$ orbital, which is weakly antibonding. Consequently, the $v(\mathrm{C} \equiv \mathrm{N})$ band shifted to higher frequencies. $\pi$-back bonding tends to decrease $v(\mathrm{C} \equiv \mathrm{N})$ because the electron enters an anti-bonding $2 \mathrm{p} \pi *$ orbital. In general, $\mathrm{CN}^{-}$is a good $\sigma$ donor and a poor $\pi$ acceptor. Thus, $v(\mathrm{CN})$ for the complexes is generally higher than the values for free $\mathrm{CN}^{-}$. The IR spectra also suggested that the cyanide ligands were oriented linearly between the divalent $\mathrm{Fe}$ of ferrocyanide moiety and $\mathrm{FeCl}_{2}$, with the $\mathrm{C}$ atom possibly coordinated to

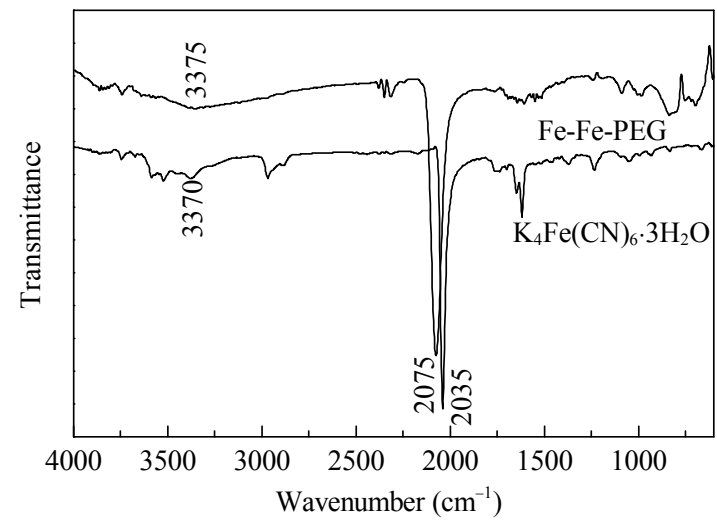

Fig. 4. FT-IR spectra of $\mathrm{K}_{4} \mathrm{Fe}(\mathrm{CN})_{6}$ and $\mathrm{Fe}-\mathrm{Fe}-\mathrm{PEG}$. the divalent Fe. FT-IR spectroscopy also provided clear evidence for the presence of water molecule in the Fe-Fe-PEG complex (Fig. 4). The $v(\mathrm{C} \equiv \mathrm{N})$ value varied with the metal ions (Fig. 5). Of all the DMC investigated, Fe-Mn-PEG has the lowest $v(\mathrm{C} \equiv \mathrm{N})\left(2058 \mathrm{~cm}^{-1}\right)$ value and Fe-Zn-PEG has the highest $v(\mathrm{C} \equiv \mathrm{N})\left(2094 \mathrm{~cm}^{-1}\right)$ value. A very broad band in the region of $3200-3600 \mathrm{~cm}^{-1}$ was observed in all DMC catalysts. This was due to the presence of

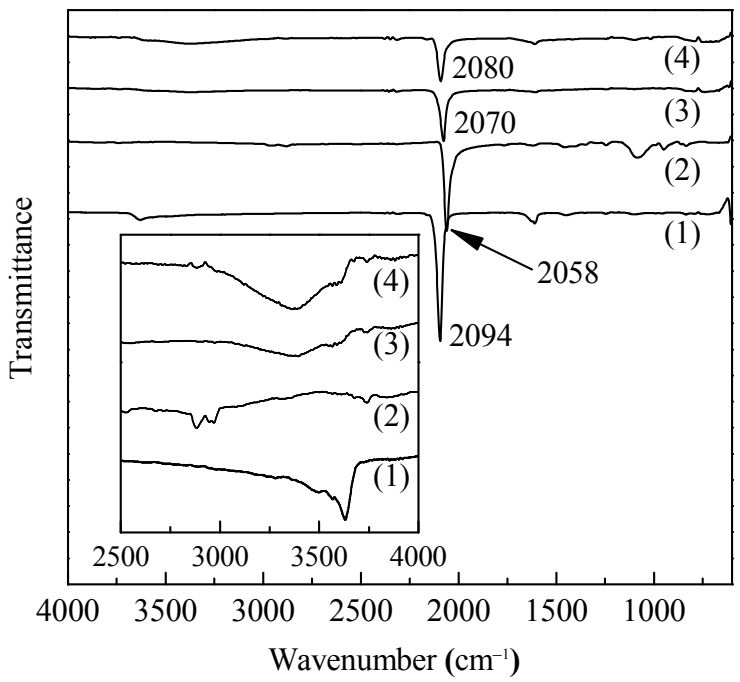

Fig. 5. FT-IR spectra of (1) Fe-Zn-PEG, (2) Fe-Mn-PEG, (3) Fe-CoPEG, and (4) Fe-Ni-PEG based DMC catalysts. Inset shows FT-IR spe ctra of these DMC catalysts in the range of $2500-4000 \mathrm{~cm}^{-1}$.

inter/intra molecular hydrogen bonding due to the presence of $\mathrm{H}_{2} \mathrm{O}$ molecule in the catalyst. However, such hydrogen bonding was extremely weak in case of the Fe-Mn-PEG catalyst (Fig. 5 inside).

Diffuse reflectance UV-Vis spectroscopy provides insight into the coordination geometry of metal ions in DMC complexes [24]. $\mathrm{K}_{4} \mathrm{Fe}(\mathrm{CN})_{6}$ showed an intense band at $236 \mathrm{~nm}$ 
and two medium intensity bands at 278 and $330 \mathrm{~nm}$. The former band corresponds to $\pi-\pi^{*}$ charge transfer in the cyanide group and the latter two bands were attributed to ligand (CN)-to-metal (Fe) charge transfer (LMCT) [25]. In the case of the Fe-Fe-PEG complex, the LMCT bands shifted towards lower energy (280 and $375 \mathrm{~nm}$, Fig. 6), which was due to the bridging of the cyanide group and the delocalization of electron density on both $\mathrm{Fe}^{2+}$ orbitals. This shift in the position of the LMCT bands provided additional support for the conclusion derived from the FT-IR result, namely, the Fe-Fe-PEG catalyst contained bridging cyano groups between both $\mathrm{Fe}^{2+}$. A broad additional absorption band was observed for the Fe-Fe-PEG catalyst in the visible region, which was due to a $d-d$ transition and indicated that Fe was in a high spin +2 oxidation state. In the case of Fe-Zn-PEG, no additional absorption band was observed, indicating that the $\mathrm{Fe}$ in the latter was in a low spin +2 oxidation state corresponding to the ${ }^{1} \mathrm{~A}_{1 \mathrm{~g}}$ ground state. The electronic transition from ${ }^{1} \mathrm{~A}_{1 \mathrm{~g}}$ to the excited triplet state is Laporte-forbidden, and hence no $d$ - $d$ transition was observed in the visible region. Fe-Ni-PEG and Fe-Mn-PEG showed one $d-d$ band at around $415 \mathrm{~nm}$ and another $d-d$ band at $>$ $800 \mathrm{~nm}$. Fe-Co-PEG showed an asymmetric, broad band at $619 \mathrm{~nm}$. Based on the positions of the $d-d$ bands in Fe-Mn-PEG, Fe-Co-PEG, and Fe-Ni-PEG, it can concluded that $\mathrm{Mn}^{2+}, \mathrm{Ni}^{2+}$, and $\mathrm{Co}^{2+}$ have octahedral coordination geometry [24].

\subsection{Catalytic investigations}

The synthesis of new and efficient multi-component reactions (MCRs) for the production of valuable scaffolds remain a challenge. These reactions have gained more use in synthetic organic chemistry. The catalytic activities of the DMC catalysts was assessed by using the MCRs for the synthesis of pharmaceutically important organic derivatives. The synthesis of $N$-[(2-hydroxy-naphthalen-1-yl)-phenylmethyl]-benzamide/urea by MCR of benzaldehyde, $\beta$-naphthol and benzamide/urea was first investigated (Scheme 1).

The influences of reaction parameters such as the role of the solvent, amount of catalyst, reaction temperature, and time were investigated to optimize the reaction condition. The coupling reaction of $\beta$-naphthol with benzaldehyde and benzamide did not take place at $298 \mathrm{~K}$. A very low yield

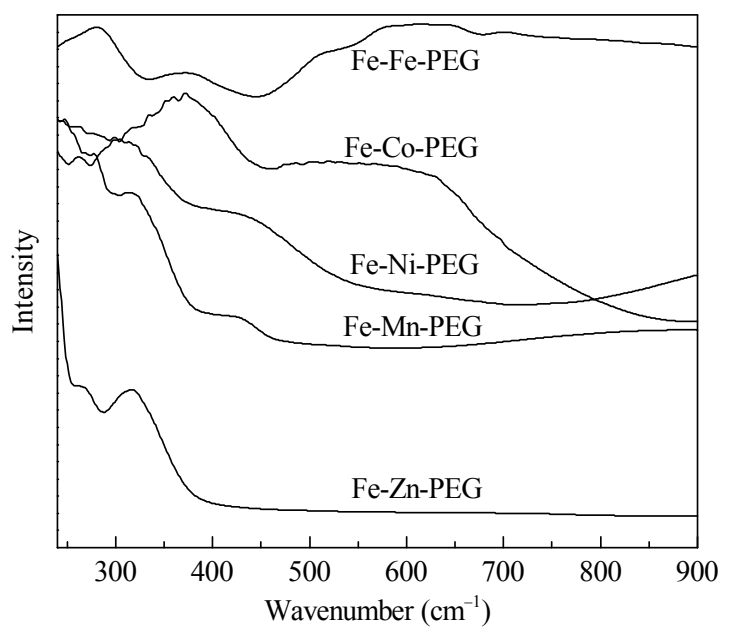

Fig. 6. Diffuse reflectance UV-Vis spectra of the various dual-metal cyanide catalysts.

$(22 \%)$ of the desired product was obtained at $323 \mathrm{~K}$. A moderate yield $(68 \%)$ was obtained when the reaction was performed at $353 \mathrm{~K}$. The influence of various catalysts in the synthesis of $\mathrm{N}$-[(2-hydroxy-naphthalen-1-yl)-phenylmethyl]-benzamide was investigated (Table 3). The catalytic activity of the DMC catalysts followed the order: Fe-Fe-PEG $>$ Fe-Mn-PEG $>$ Fe-Zn-PEG $>$ Fe-Co-PEG $>$ Fe-Ni-PEG. A possible mechanism for this transformation is the reaction of $\beta$-naphthol with aromatic aldehydes in the presence of a DMC catalyst to give ortho-quinonemethides (o-QMs). The $o$-QMs react with benzamide/urea by conjugate addition to form 1-amidoalkyl-2-naphthol derivatives. When urea was used instead of benzamide, $N$-[(2-hydroxynaphthalen-1-yl)-phenylmethyl]-urea was formed. The reaction with urea occurred faster than that with the benzamide (Table 3), and a similar trend in catalytic activity was obtained, i.e., Fe-Fe-PEG $>$ Fe-Mn-PEG $>$ Fe-Zn-PEG $>$ Fe-Co-PEG $>$ Fe-Ni-PEG. Fe-Fe-PEG and Fe-Mn-PEG retained their activity to the third recycle (Table 3 ). The effect of aromatic substitution on the reaction was also studied.

The Betti reaction is a special case of the Mannich reaction. The synthesis of 1-(phenyl (piperidin-1-yl) methyl) naphthalene-2-ol by the MCR of benzaldehyde, $\beta$-naphthol, and piperidine in water using a DMC catalyst was attempted (Scheme 2). In the synthesis of the Betti base, the first step

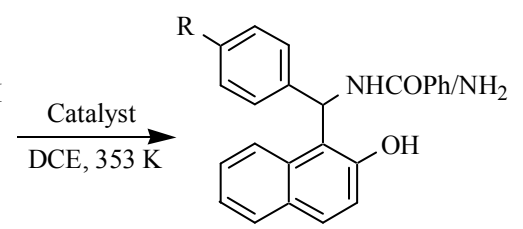

Scheme 1. Multi-component coupling reactions of aromatic aldehydes, $\beta$-naphthol, and benzamide/urea. 
Table 3 Synthesis of $N$-[(2-hydroxy-naphthalen-1-yl)-aryl-methyl]-benzamide/urea over the acid catalysts investigated in this study

\begin{tabular}{cccccc}
\hline \multirow{2}{*}{ Entry } & \multirow{2}{*}{ Catalyst } & $\mathrm{R}$ & Temperature (K) & Benzamide used as reactant & Urea used as reactant \\
\cline { 4 - 6 } & & & & 0 & - \\
2 & Fe-Fe-PEG & $\mathrm{H}$ & 298 & 22 & 67 \\
3 & Fe-Fe-PEG & $\mathrm{H}$ & 323 & 68 & 64 \\
$4^{\mathrm{a}}$ & Fe-Fe-PEG & $\mathrm{H}$ & 353 & 64 & 54 \\
5 & Fe-Mn-PEG & $\mathrm{H}$ & 353 & 52 & - \\
$6^{\mathrm{a}}$ & Fe-Mn-PEG & $\mathrm{H}$ & 353 & 48 & 46 \\
7 & Fe-Zn-PEG & $\mathrm{H}$ & 353 & 45 & 39 \\
8 & Fe-Co-PEG & $\mathrm{H}$ & 353 & 38 & 34 \\
9 & Fe-Ni-PEG & $\mathrm{H}$ & 353 & 40 & 72 \\
10 & Fe-Fe-PEG & $\mathrm{Cl}$ & 353 & 72 & 64 \\
11 & Fe-Fe-PEG & $\mathrm{OCH}$ & 353 & 65 & \\
\hline
\end{tabular}

Reaction conditions: $10 \mathrm{mmol} \beta$-naphthol, $10 \mathrm{mmol}$ benzaldehyde, $12 \mathrm{mmol}$ benzamide/urea, $0.5 \mathrm{mmol}$ catalyst, $15 \mathrm{ml}$ 1,2-dichloroethane solvent, reaction temperature $353 \mathrm{~K}$, run $24 \mathrm{~h}$ for benzamide and $12 \mathrm{~h}$ for urea. ${ }^{\mathrm{a}}$ Catalytic activity data in third recycle.

of the reaction is the imine formation, which is catalyzed by a Lewis acid. Then, $\beta$-naphthol reacts with the imine to form the substituted naphthol derivative. The coupling reaction of $\beta$-naphthol with benzaldehyde and piperidine proceeded smoothly at room temperature to give the corresponding1-(phenyl (piperidin-1-yl) methyl) naphthalen-2-ol in good yield and in very much less time with the DMC catalysts. All the catalysts investigated in this study were active (Table 4). Aside from the desired product, no other product was formed. The catalytic activity of the DMC catalysts followed the order: Fe-Fe-PEG $>$ Fe-Mn-PEG $>$ Fe-Zn-PEG $>$ Fe-Co-PEG $>$ Fe-Ni-PEG. Fe-Fe-PEG exhibited no loss in activity to the third recycling.

The acid-catalyzed, 3-component reaction of an aldehyde, a $\beta$-ketoester, and urea is a rapid and facile synthesis of dihydropyrimidones known to be the Biginelli condensation reaction. The synthesis of dihydropyrimidinone was done by the cyclocondensation reaction of ethylacetoacetate, benzaldehyde, and urea in acetonitrile using a DMC catalyst (Scheme 3). In addition to the Biginelli product (major), the Hantzsch product (minor) was also formed with the acid catalysts [26]. Efforts were made to use the DMC catalysts
Table 4 Synthesis of 1-(aryl(piperidin-1-yl) methyl) naphthalen-2-ol over the acid catalysts investigated in this study

\begin{tabular}{cccc}
\hline Entry & Catalyst & $\mathrm{R}$ & Yield (\%) \\
\hline 1 & Fe-Fe-PEG & $\mathrm{H}$ & 65 \\
$2^{\mathrm{a}}$ & Fe-Fe-PEG & $\mathrm{H}$ & 60 \\
3 & Fe-Mn-PEG & $\mathrm{H}$ & 60 \\
4 & Fe-Zn-PEG & $\mathrm{H}$ & 58 \\
5 & Fe-Co-PEG & $\mathrm{H}$ & 50 \\
6 & Fe-Ni-PEG & $\mathrm{H}$ & 45 \\
7 & Fe-Fe-PEG & $\mathrm{Cl}$ & 70 \\
8 & Fe-Fe-PEG & $\mathrm{OCH}_{3}$ & 54 \\
\hline
\end{tabular}

Reaction conditions: $10 \mathrm{mmol} \beta$-naphthol, $13 \mathrm{mmol}$ aldehyde, $10 \mathrm{mmol}$ piperidine, $0.5 \mathrm{mmol}$ catalyst, $15 \mathrm{ml}$ water, $298 \mathrm{~K}$, run $4 \mathrm{~h}$.

${ }^{a}$ Catalytic activity data in third recycle.

in a cyclocondensation reaction. No side product was found when the reaction was catalyzed by Fe-Fe-PEG and Fe-Mn-PEG catalysts, while minute amounts of side products were found when the reactions were carried out in the presence of the other DMC catalysts (Table 5). The catalytic activity of the DMC catalysts followed the order: Fe-Fe-PEG $>$ Fe-Mn-PEG $>$ Fe-Zn-PEG $>$ Fe-Co-PEG $>$ Fe-Ni-PEG. Fe-Fe-PEG and Fe-Zn-PEG exhibited no loss in

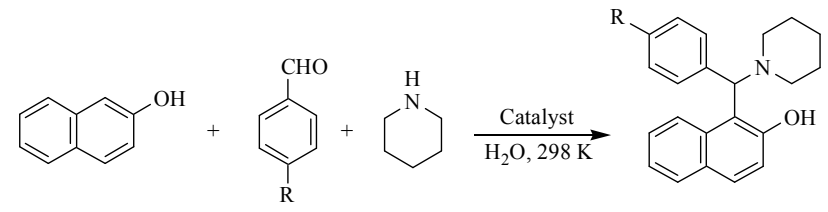

Scheme 2. Multi-component coupling reactions of aromatic aldehydes, $\beta$-naphthol, and piperidine.

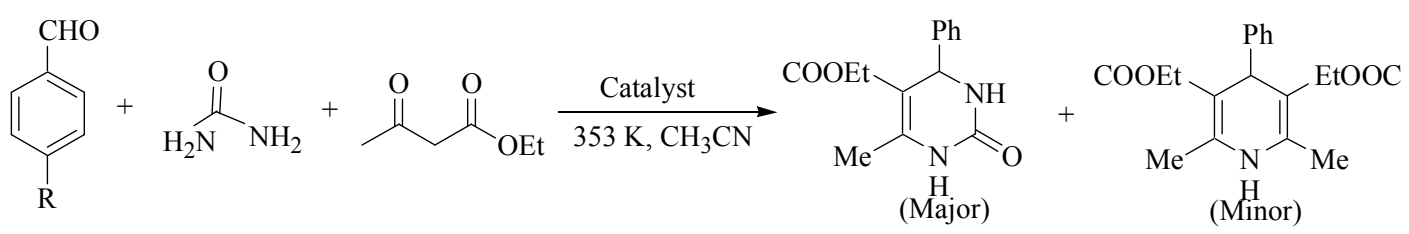

Scheme 3. Cyclocondensation reaction of ethyl acetoacetate, aromatic aldehydes, and urea. 
Table 5 Synthesis of 5-(ethoxycarbony)-6-methyl-4-phenyl-3,4-dihydropyrimidin-2(1H)-one over the acid catalysts investigated in this study

\begin{tabular}{|c|c|c|c|c|c|}
\hline \multirow{2}{*}{ Entry } & \multirow{2}{*}{ Catalyst } & \multirow{2}{*}{$\mathrm{R}$} & \multirow{2}{*}{ Total yield (\%) } & \multicolumn{2}{|c|}{ Products yield (\%) } \\
\hline & & & & Major product & Minor product \\
\hline 1 & Fe-Fe-PEG & $\mathrm{H}$ & 50 & 50 & 0 \\
\hline $2^{\mathrm{a}}$ & Fe-Fe-PEG & $\mathrm{H}$ & 47 & 47 & 0 \\
\hline 3 & Fe-Mn-PEG & $\mathrm{H}$ & 41 & 41 & 0 \\
\hline 4 & Fe-Zn-PEG & $\mathrm{H}$ & 30 & 28 & 2 \\
\hline $5^{\mathrm{a}}$ & Fe-Zn-PEG & $\mathrm{H}$ & 26 & 25 & 1 \\
\hline 6 & Fe-Co-PEG & $\mathrm{H}$ & 24 & 23 & 1 \\
\hline 7 & $\mathrm{Fe}-\mathrm{Ni}-\mathrm{PEG}$ & $\mathrm{H}$ & 22 & 18 & 4 \\
\hline 8 & Fe-Fe-PEG & $\mathrm{Cl}$ & 50 & 53 & 0 \\
\hline 9 & Fe-Fe-PEG & $\mathrm{OCH} 3$ & 50 & 48 & 0 \\
\hline
\end{tabular}

Reaction conditions: $1 \mathrm{mmol}$ ethylacetoacetate, $1 \mathrm{mmol}$ benzaldehyde, $1.5 \mathrm{mmol}$ urea, $0.05 \mathrm{mmol}$ catalyst, $3 \mathrm{ml}$ acetonitrile solvent, reaction temperature $353 \mathrm{~K}$, run $12 \mathrm{~h} .{ }^{\mathrm{a}}$ Catalytic activity data in third recycle.

activity to the third recycle. All these reactions (Tables 3-5) proceeded easily, delivered good product yields and could accommodate a wide range of aromatic aldehydes bearing both electron-donating and electron-withdrawing substituents. Substrates with an electron-withdrawing group gave higher yields. From the catalytic investigations, it can be concluded that Fe-Fe-PEG was the best catalyst for the acid catalyzed multi-component coupling reactions. A coordinatively unsaturated $\mathrm{Fe}^{2+}$ was the probable active site for these reactions. The catalytic activity and physico-chemical characterization revealed that both the acidity due to $\mathrm{Fe}^{2+}$ ions and the high surface area were responsible for the high catalytic activity of the Fe-Fe-PEG catalyst.

\section{Conclusions}

Several dual metal cyanide catalysts were prepared and their catalytic activities for acid catalyzed multi-component coupling reactions were determined. Several multi-component coupling reactions for pharmaceutically important organic derivatives such as $N$-[(2-hydroxy-naphthalen-1-yl)aryl-methyl]-benzamide/urea, 1-(aryl (piperidin-1-yl) methyl) naphthalen-2-ol, and 5-(ethoxycarbony)-6-methyl4-aryl-3, 4-dihydropyrimidin- $2(1 \mathrm{H})$-one were investigated. These reactions were easy to perform. In all these reactions, the Fe-Fe-PEG catalyst was the best catalyst. The role of PEG surfactant molecules in the synthesis was probably to increase the surface area and acid sites density to enhance catalytic activity. The catalytic activity and physico-chemical characterization revealed that the acidity and large surface area were responsible for the high catalytic activity of the Fe-Fe-PEG catalyst. The catalysts can be reused with negligible loss in activity.

\section{References}

1 Hinney H R, Wardius D S. US 5158922.1992

2 Le-Khac B. US 5627 120. 1997
3 Ooms P, Hofmann J, Schafer W. US 7169 956. 2005

4 Combs G. US 7034 103. 2006

5 O'Connor J M, Lickei D L. Polyols Derived from Double Metal Cyanide Catalysts in Proceedings of UTECH 2000. The Hague: Rapra Conference Proceedings, 2000. 6/1-6/9

6 Gravereau P P, Emmanuel G. Acta Crystallogrc, 1984, C40: 1306

7 Herold R J. US 3278 459. 1966

8 Kuyper J, Boxhoon G. J Catal, 1987, 105: 163

9 Huang Y J, Qi G R, Chen L S. Appl Catal A, 2003, 240: 263

10 Suh H S, Ha J Y, Yoon J H, Ha C S, Suh H, Kim I I. React Funct Polym, 2010, 70: 288

11 Darensbourg D J, Adams M J, Yarbrough J C. Inorg Chem, 2001, 40: 6543

12 Kim I I, Yi M J, Byun S H, Park D W, Kim B U, Ha C S. Macromol Symp, 2005, 224: 181

13 Kim I I, Yi M J, Lee K J, Park D W, Kim B U, Ha C S. Catal Today, 2006, 111: 292

14 Kim I I, Ahn J T, Ha C S, Yang C S, Park I. Polymer, 2003, 44: 3417

15 Srivastava R, Srinivas D, Ratnasamy P. J Catal, 2006, 241 : 34

16 Sreeprasanth P S, Srivastava R, Srinivas D, Ratnasamy P. Appl Catal A, 2006, 314: 148

17 Domling A, Ugi I. Angew Chem, Int Ed, 2000, 39: 3168

18 Bienayme H, Hulme C, Oddon G, Schmitt P. Chem Eur J, 2000, 6: 3321

19 Salama T A, Elmorsy S S, Khalil A G M, Ismail M A. Tetrahedron Lett, 2007, 48: 6199

20 Nandi G C, Samai S, Kumar R, Singh M S. Tetrahedron Lett, 2009, 50: 7220

21 Kumar A, Gupta M K, Kumar M. Tetrahedron Lett, 2010, 51: 1582

22 Polshettiwar V, Varma R S. Tetrahedron Lett, 2007, 48: 7343

23 Nakamoto K. Infrared and Raman Spectra of Inorganic and Coordination Compounds. 3rd Ed. New York: Wiley, 1978

24 Lever A B P. Inorganic Electronic Spectroscopy. 2nd Ed. Amsterdam: Elsevier. 1984

25 Folkers K, Johnson T B. J Am Chem Soc, 1933, 55: 3784

26 Srivastava R. Catal Lett, 2010, 139: 17 